\title{
Association between metabolic syndrome and periodontitis: a systematic review and meta-analysis
}

\section{Luciana Dondonis DAUDT(a) Marta Liliana MUSSKOPF(b) Marina MENDEZ ${ }^{(a)}$ Luciana Loss Reck REMONTI(c) Cristiane Bauermann LEITÃO(c) Jorge Luiz GROSS(c) Patricia WEIDLICH(a) Rui Vicente OPPERMANN(a)}

(a) Universidade Federal do Rio Grande do Sul - UFRGS, Dental School, Department of Periodontology, Porto Alegre, RS, Brazil.

(b) Universidade Luterana do Brasil - Ulbra, Dental School, Porto Alegre, RS, Brazil.

(c) Universidade Federal do Rio Grande do Sul . UFRGS, Hospital de Clínicas de Porto Alegre, Division of Endocrinology, Porto Alegre, Brazil.

Declaration of Interest: The authors certify that they have no commercial or associative interest that represents a conflict of interest in connection with the manuscript.

Corresponding Author:

Patricia Weidlich

Email: patricia.weidlich@ufrgs.br

Submitted: October 17, 2017

Accepted for publication: February 20, 2018

Last revision: March 14, 2018
Abstract: The aim of the present study was to evaluate the association between metabolic syndrome (MS) and periodontitis (PD), through a systematic review and meta-analysis. Original observational studies assessing the association between MS and PD in adults, published before May 11 ${ }^{\text {th }}$ (2017), were identified through electronic searches of MEDLINE, EMBASE and Cochrane Library databases. The PRISMA (Preferred Reporting Items for Systematic Reviews and Meta-Analyses) guideline was used. For studies to be included, they had to mention the criteria used to diagnose MS and to have used at least one clinical measure to diagnose PD. There was no language restriction. Three reviewers independently identified eligible studies for possible inclusion in the systematic review and meta-analysis. The quality of the studies was evaluated by the Newcastle-Ottawa scale for observational studies. A random model meta-analysis was conducted. The strategies used to investigate heterogeneity were sequential analysis, subgroup analysis, univariate meta-regression and sensitivity analysis. Thirty-three studies met the inclusion criteria for the systematic review, and 26 had enough information to be included in the meta-analysis, totaling 52,504 patients. MS and PD were associated with an odds ratio of $1.38(95 \% \mathrm{CI}$ 1.26-1.51; I2 = 92.7\%; $\mathrm{p}<0.001$ ). Subgroup analysis showed that complete periodontal examination (I2 $=70.6 \%$; $<0.001$ ) partially explained the variability between studies. The present findings suggest an association between MS and PD. Individuals with MS are 38\% more likely to present PD than individuals without this condition. Prospective studies should be conducted to establish cause and effect relations between MS and PD.

Keywords: Metabolic Syndrome; Periodontal Diseases; Periodontal Attachment Loss; Insulin Resistance; Review Literature as Topic.

\section{Introduction}

Periodontitis (PD) is a bacteria-induced chronic inflammatory disease, which destroys the bone and connective tissue that support the teeth. It is estimated that approximately 20 to $60 \%$ of the world's population may have some degree of destructive periodontal disease, ${ }^{1,2,3,4}$ and that $7.4 \%$, representing 538 million individuals, have more severe forms. ${ }^{5}$ The condition is generally diagnosed by a clinical dental examination, since such signs and symptoms as dental mobility, halitosis, altered tooth positioning and 
frequent abscesses tend to be noticed by patients only in the final stages of the disease. Patients presenting moderate and severe PD have been found to produce higher systemic levels of inflammatory and immune markers, such as C-reactive protein, interleukin-6, interleukin $1 \beta$ and tumoral necrosis factor (TNF) ${ }^{6,7}$ PD treatment is able to reduce these markers. ${ }^{8}$

The low-grade inflammatory status induced by untreated PD creates a systemic inflammatory phenotype that has been associated with several other systemic diseases/disorders, including cardiovascular diseases, ${ }^{9}$ obesity, ${ }_{10}^{10}$ insulin resistance ${ }^{11}$ and metabolic syndrome (MS). ${ }^{12,13,14,15,16}$ MS consists of a group of metabolic abnormalities associated with the greater likelihood of developing type 2 diabetes and cardiovascular disease. ${ }^{17}$ According to the most recent guidelines issued in 2009 by the International Diabetes Federation (IDF) and the American Heart Association/ National Heart, Lung and Blood Institute (AHA/NHLBI), MS is defined as the combination of the following conditions: increased plasma glucose, hypertension, hy pertriglyceridemia, low HDL cholesterol and/or elevated abdominal circumference. ${ }^{18}$ Patients must have at least three of these abnormalities to be diagnosed with MS. Its prevalence varies according to the population studied and the criteria used for diagnosis; however, it is estimated that a quarter of the world population has MS. The risk of developing this condition is thought to increase proportionally with age. ${ }^{19}$

The association between MS and PD has become an important topic of research in the scientific literature. The presence of continuous low-grade inflammatory status could lead to the development of insulin resistance and upset the balance of interactions between cytokines and the periodontium. ${ }^{1719}$ PD may also influence one's general health status by affecting the host's susceptibility to systemic diseases resulting from the accumulation of gram-negative bacteria and inflammatory mediators in the bloodstream, both of which lead to inflammation. ${ }^{11}$ These features also characterize MS. ${ }^{17,19,20}$

The results of the studies that evaluated the relation between PD and MS are widely discrepant. 12,13,14,15,16,21,22,23 Considering that this relationship is characterized differently by conflicting findings, there is still no consensus on the magnitude of the association between MS and PD. Since systematic reviews are important tools to reconcile these seemingly divergent findings, the aim of the present study was to assess the association between MS and PD through a systematic review and meta-analysis of observational studies.

\section{Methodology}

\section{Focused question}

Is there an association between metabolic syndrome and periodontal disease demonstrated in observational studies? The PECO strategy for the research question was: in patients diagnosed with periodontal disease and/or metabolic syndrome, the exposure was the presence of PD and/or MS, compared with patients with no PD and/or no MS. The outcome was any measure of prevalence of PD and MS.

\section{Search strategy}

The authors undertook a systematic review to locate original studies on the association between PD and MS. The study protocol was approved by the Research Committee of UFRGS (Study 22842). Observational studies were identified, focusing on participants diagnosed with PD and MS. The outcome was PD and/ or MS, since cross-sectional studies have no temporal component, and do not allow both directions of the association to be investigated. The present systematic review was conducted based on guidelines established for meta-analyses of observational studies ${ }^{24}$ and is presented according to the PRISMA Statement.

Electronic databases were systematically searched for scientific articles published before May $11^{\text {th }}$, 2017, which evaluated the association between MS and PD. The search was conducted in MEDLINE (accessed via PubMed), EMBASEand the Cochrane Library, and used the following keywords and MeSH terms (*): periodontal attachment loss* OR periodontics* OR gingivitis* OR periodontal diseases* $O R$ gingival bleeding $O R$ periodontitis* $A N D$ metabolic syndrome $x^{*}$ OR metabolic syndrome $O R$ syndrome $x$ OR plurimetabolic. There was no language restriction. Articles in Chinese, Polish and Persian were translated with online translation software.

Relevant unpublished studies were located by reviewing abstracts in the annals of main scientific events in the field since 2006. The proceedings of 
the following conferences were searched: EuroPerio, promoted by the European Federation of Periodontology; IADR General Session, promoted by the International Association for Dental Research; AAP Annual Meeting, promoted by the American Academy of Periodontology; AHA Scientific Sessions, promoted by the American Heart Association; the ADA Scientific Session, promoted by the American Diabetes Association; and the EASD Annual Meeting, promoted by the European Association for the Study of Diabetes. The reference lists of the studies included in the review were also searched.

Two reviewers (MLM and MM) independently identified eligible studies for possible inclusion in the systematic review and meta-analysis, based on their titles and abstracts. The articles whose abstracts were selected were retrieved for full text evaluation. The studies selected for detailed analysis by these two investigators (MLM and MM) had a kappa agreement of 0.95 . Disagreements were settled by a third investigator (RVO).

Studies were considered eligible when meeting the following criteria: original epidemiological study, observational, cross-sectional, case-control, or cohort design, adult sample, use of at least one clinical diagnostic criterion for PD that was clearly defined to warrant reproducibility, and clearly defined criteria for the diagnosis of MS. The studies excluded from the analysis, and the reasons for their exclusion, are reported in Figure 1.

\section{Data extraction}

The data were extracted independently by two investigators (MLM and PW), and included the participants' age, gender and smoking status, nature of the experimental design, the diagnostic criteria used for PD and MS, total number of participants, number of participants with PD and MS, and study outcomes.

\section{Quality assessment}

The quality of the studies was evaluated using the Newcastle-Ottawa scale ${ }^{25}$ for observational studies. The scale assigns a score of zero to nine stars to each article, whereby a greater number of stars indicate a higher quality study.

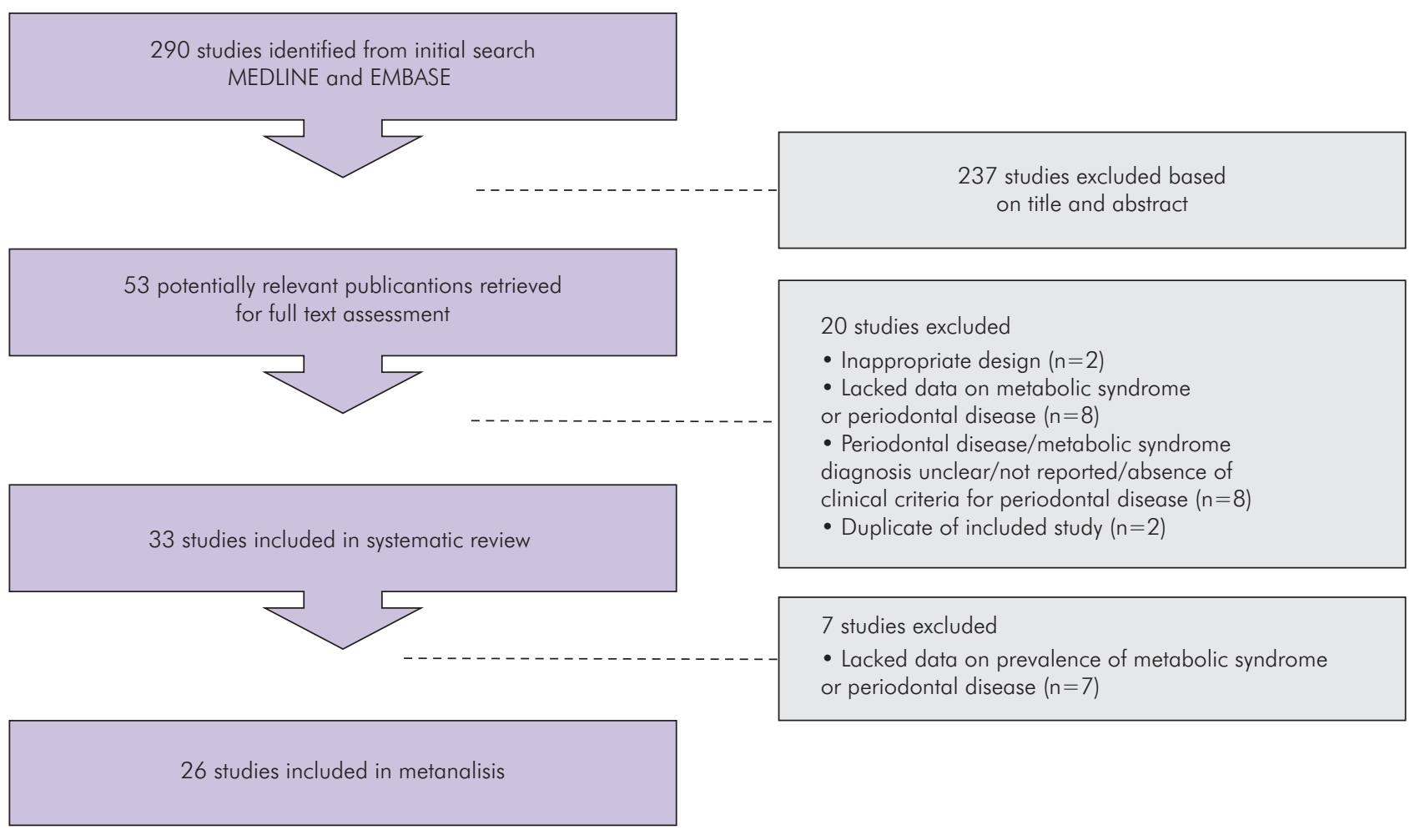

Figure 1. Flowchart of the search for studies, their selection and inclusion. 


\section{Statistical analysis}

The general effect size was calculated using the reported PD and MS prevalence rates. Baseline values were used for cohort and case-control studies. When these data were not available, the authors were contacted by email. Random effect models were used in the analyses to account for between-study variability. Four strategies were used to investigate heterogeneity, considered high whenever $\mathrm{I}^{2}$ was greater than $50 \%{ }^{26}$ The first strategy involved univariate meta-regression, performed to assess the effect of age, gender and smoking status on estimates of heterogeneity. The second step involved successive removal of each study, so that its impact on $\mathrm{I}^{2}$ values could be observed. In the third step, a subgroup analysis took into account the periodontal examination and the MS diagnosis criteria. The fourth and last step of the heterogeneity analysis involved the sensitivity analyses, which included only those studies that received scores of eight or nine stars on the Newcastle-Ottawa scale. ${ }^{27}$ The possibility of publication bias was evaluated using a funnel plot of the effect size plotted against the standard error of each trial. Begg's and Egger's tests were used to evaluate funnel plot asymmetry, with significant publication bias defined as a p-value $<0.1$. The analyses were performed using STATA software (version 12; Stata Corp, College Station, USA).

\section{Results}

The electronic search retrieved 290 articles from PubMed and EMBASE. No additional articles were found in the Cochrane Library or in any other database searched. Two hundred and thirty-seven studies were excluded based on titles and abstracts, resulting in 53 articles for full-text evaluation. A total of 33 studies met the eligibility criteria ( 29 cross-sectional, two case-control and two cohort studies, totalizing 52,504 participants; Figure 1) and were included in the systematic review, and 26 were included in the meta-analysis. Seven studies were not included in the meta-analysis, because there was no prevalence data for PD and/or MS. ${ }^{28,29,30,31,32,33,34}$

Table 1 describes the studies included in the review. The articles were published between 2007 and 2017, and most were conducted in Asian countries. PD was diagnosed by a complete periodontal examination in seventeen studies, $12,23,28,31,32,33,35,36,37,38,39,40,41,42,43,44,45$ and by a partial periodontal examination in sixteen studies. $13,14,15,16,22,29,30,34,46,47,48,49,50,51,52,53$ Concerning the definition criteria for PD, eleven studies $^{12,14,15,22,29,30,34,49,50,51,52}$ used the Community Periodontal Index (CPI) ${ }^{54}$ and seven studies ${ }^{23,37,40,42,43,45,47}$ used the classification system proposed by Page and Eke. ${ }^{55}$ The remaining fifteen studies established other diagnostic criteria for PD. $13,16,28,31,32,33,35,36,38,39,41,44,46,48,49$ Thirteen studies diagnosed MS using the National Cholesterol Education Program - Adult Treatment Panel III (NCEP ATP III) criteria, 12,13,15,16,22,23,28,32,33,37,46,49,51 ten used the 2005 IDF criteria, $29,30,35,38,39,40,41,42,47,48$ four used both the IDF 2009 and AHA/NHBLI 2009 criteria, ${ }^{14,36,50,52}$ three used the IDF 2009 criteria ${ }^{44,45,53}$ and three studies used other classification criteria. ${ }^{31,34,43}$ Table 2 shows the quality assessment of the included studies. Fifteen studies scored seven or more stars, indicating that $45.5 \%$ of the studies had very good quality. All the studies controlled the confounding variables. The most commonly controlled factors were age, gender and smoking habits. No article presented poor quality according to the NewcastleOttawa scale.

The estimated PD prevalence ranged from 5.77\% to $92.89 \%$, whereas the MS prevalence ranged from $5.22 \%$ to $83.21 \%$. The meta-analysis revealed a positive association between MS and PD, with an odds ratio (OR) of 1.38 (95\%CI1.26-1.51; I I = 92.7\%; p heterogeneity $<0.001$ ) (Figure 2). Meta-regression showed that age explained $22 \%$ of the heterogeneity of the results $(p=0.01)$, whereas gender $(p=0.09)$ and smoking status $(p=0.40)$ failed to explain heterogeneity. In addition, none of the studies in itself could explain the heterogeneity when rerunning the meta-analysis by excluding one study at a time. Subgroup analyses were conducted by dividing the studies according to periodontal examination (complete or partial) or by the criteria used to define MS. When PD was diagnosed by a complete dentition examination, an OR of 1.16 (95\%CI $1.08-1.25 ; \mathrm{I}^{2}=70.6 \%$ ) was obtained (Figure 3). Studies that used a partial periodontal examination showed an OR of 1.58 (95\%CI 1.38-1.82; $\mathrm{I}^{2}=90.8 \%$ ). The magnitude of association between the two conditions, according to the MS criteria used, was 1.38 (95\%CI 


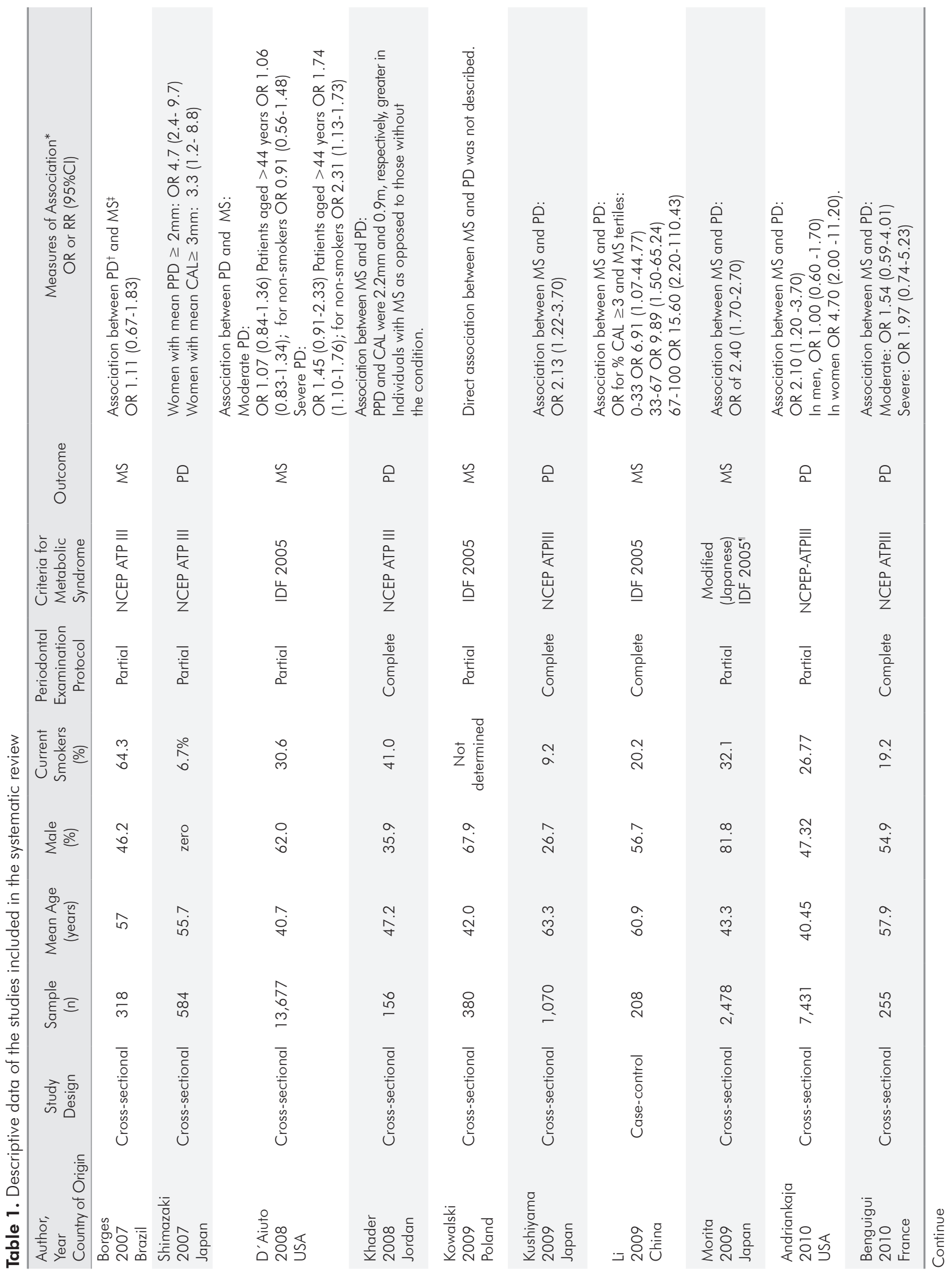




\begin{tabular}{|c|c|c|c|c|c|c|c|c|c|c|c|c|}
\hline 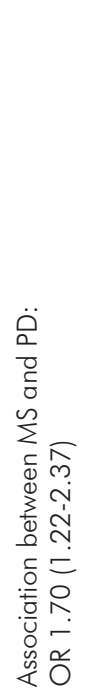 & 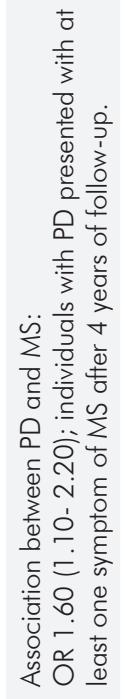 & 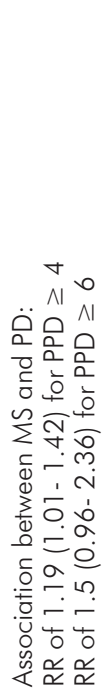 & 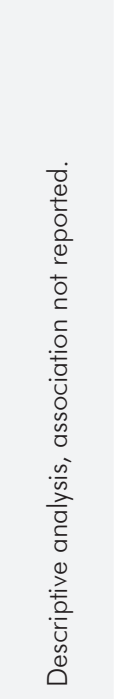 & 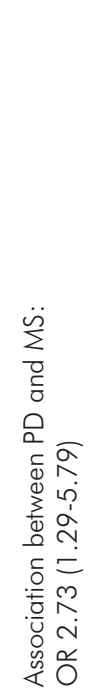 & 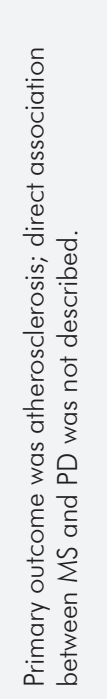 & 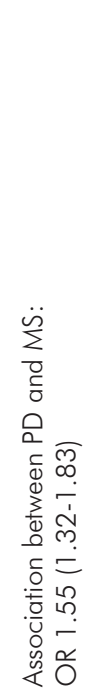 & 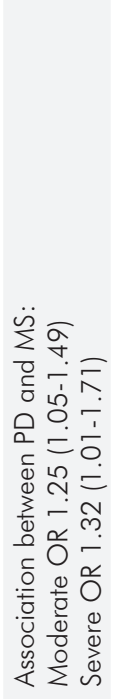 & 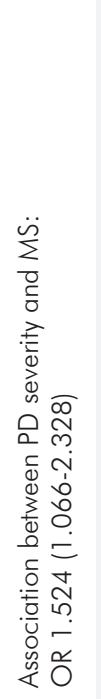 & 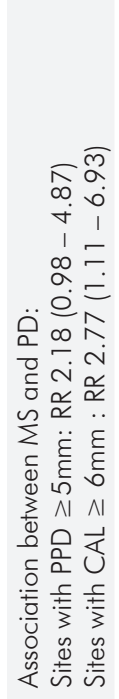 & 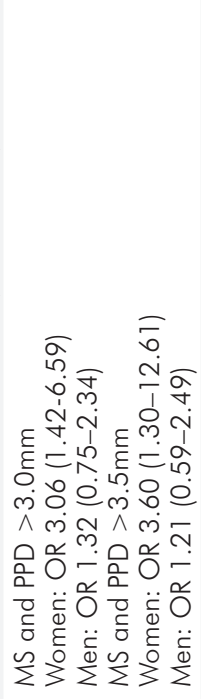 & 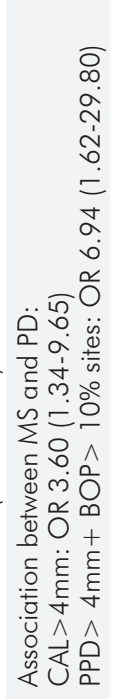 & 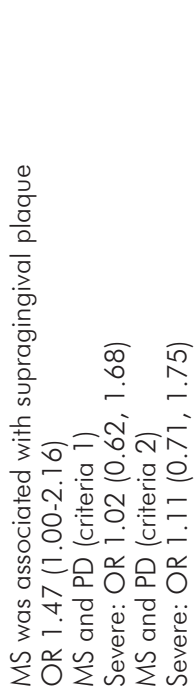 \\
\hline ฉ & $\sum^{n}$ & $\stackrel{\circ}{Q}$ & $\sum_{\Sigma}^{n}$ & $\sum^{n}$ & 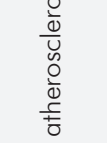 & 음 & $\Sigma^{N}$ & $\stackrel{\circ}{2}$ & $\stackrel{0}{2}$ & 은 & ㅇ & $\sum^{n}$ \\
\hline 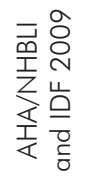 & 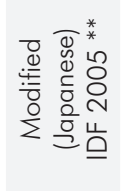 & $\stackrel{0}{\stackrel{1}{3}}$ & 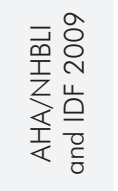 & $\begin{array}{l}\text { 三 } \\
\text { 交 } \\
\text { 岀 } \\
\text { z }\end{array}$ & 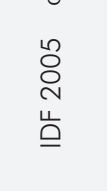 & $\begin{array}{l}\text { 三 } \\
\text { 咅 } \\
\text { 岀 } \\
\text { z }\end{array}$ & $\begin{array}{l}\equiv \\
\equiv \\
0 \\
\text { 京 } \\
\text { 岀 } \\
z\end{array}$ & $\begin{array}{l}\stackrel{2}{0} \\
\stackrel{\overbrace{}}{N} \\
\stackrel{山}{0}\end{array}$ & 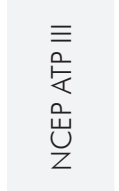 & 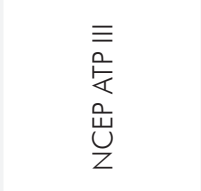 & 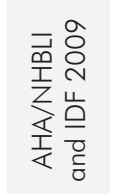 & $\begin{array}{l}\equiv \\
\equiv \\
0 \\
\text { 京 } \\
\text { 岂 } \\
\text { Z }\end{array}$ \\
\hline 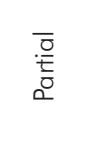 & $\begin{array}{l}\overline{\bar{\partial}} \\
\overline{\bar{t}} \\
\overline{0}\end{array}$ & $\frac{\frac{0}{0}}{\frac{0}{0}}$ & $\begin{array}{l}\overline{\bar{\sigma}} \\
\overline{\bar{E}} \\
\overline{0}\end{array}$ & $\begin{array}{l}\overline{\bar{\sigma}} \\
\overline{\underline{\underline{t}}} \\
\alpha\end{array}$ & $\begin{array}{l}\frac{0}{\frac{0}{0}} \\
\frac{0}{\hat{Q}} \\
0\end{array}$ & $\begin{array}{l}\overline{\bar{\sigma}} \\
\overline{\bar{t}} \\
\overline{0}\end{array}$ & $\begin{array}{l}\overline{\bar{\sigma}} \\
\overline{\bar{t}} \\
\overline{0}\end{array}$ & $\frac{\frac{0}{0}}{\frac{0}{0}}$ & $\frac{\frac{\omega}{0}}{\frac{0}{\varepsilon}}$ & $\frac{\frac{0}{0}}{\frac{0}{0}}$ & 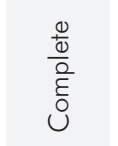 & $\begin{array}{l}\frac{0}{\frac{0}{0}} \\
\frac{0}{\tilde{g}} \\
0\end{array}$ \\
\hline 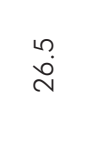 & $\frac{m}{m}$ & $\stackrel{\frac{O}{N}}{N}$ & $\begin{array}{l}\frac{0}{0} \\
\frac{0}{0} \\
\frac{0}{0} \\
\frac{0}{2} \\
z\end{array}$ & $\begin{array}{l}\circ \\
\stackrel{\sim}{a}\end{array}$ & ف. & ㅇ. & $\stackrel{\vec{\sim}}{\sim}$ & ָ̃ & 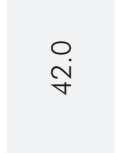 & 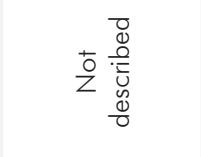 & $\begin{array}{l}\infty \\
\infty \\
\infty\end{array}$ & $\bar{i}$ \\
\hline$\hat{\stackrel{m}{q}}$ & $\stackrel{\circ}{i}$ & ๗ั & $\stackrel{\stackrel{\leftrightarrow}{+}}{\mathrm{H}}$ & $\begin{array}{c}\text { Y } \\
\text { ơ }\end{array}$ & $\stackrel{\stackrel{\leftrightarrow}{*}}{\mathrm{H}}$ & $\stackrel{n}{\stackrel{n}{m}}$ & ò & 吕 & $\stackrel{\circ}{\stackrel{\sim}{N}}$ & $\stackrel{\alpha}{\stackrel{p}{\gamma}}$ & $\stackrel{\stackrel{\leftrightarrow}{G}}{\mathrm{G}}$ & $\stackrel{\circ}{\stackrel{\circ}{N}}$ \\
\hline m & 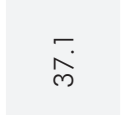 & $\begin{array}{l}\stackrel{0}{0} \\
\dot{+}\end{array}$ & 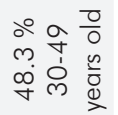 & $\begin{array}{l}\infty \\
\infty \\
\infty \\
i n\end{array}$ & $\underset{i n}{\infty}$ & $\begin{array}{l}0 \\
\dot{\varphi g}\end{array}$ & $\stackrel{\nabla}{\stackrel{\varpi}{\sigma}}$ & 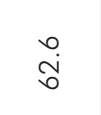 & $\begin{array}{l}m \\
\stackrel{\leftrightarrow}{n}\end{array}$ & $\begin{array}{l}n \\
\text { aे. }\end{array}$ & fे & $\begin{array}{l}n \\
\text { L } \\
0\end{array}$ \\
\hline ా & 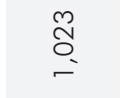 & in & $\underset{\sim}{\stackrel{N}{N}}$ & 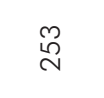 & เิ & $\frac{\infty}{\stackrel{\infty}{N}}$ & ্ָ & ஜू & $\stackrel{\infty}{\infty}$ & 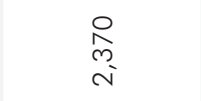 & $\stackrel{\sim}{\simeq}$ & 怘 \\
\hline 兑 & 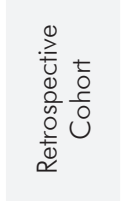 & 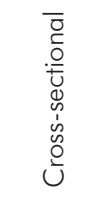 & 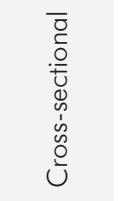 & 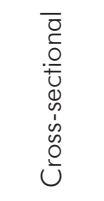 & 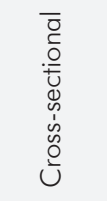 & 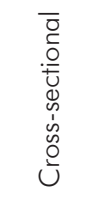 & 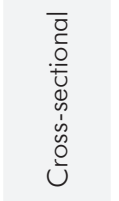 & 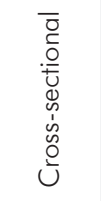 & 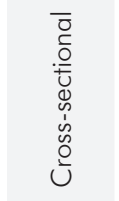 & 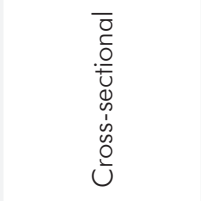 & 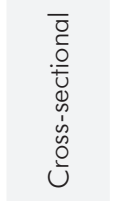 & 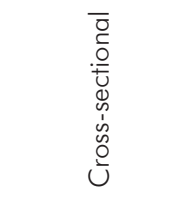 \\
\hline 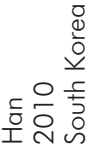 & 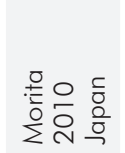 & 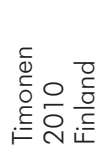 & 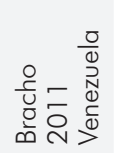 & 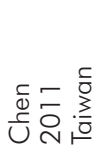 & 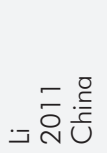 & 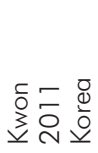 & 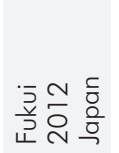 & ¿ & 흠유] & 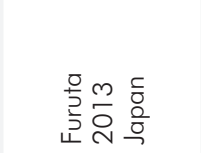 & 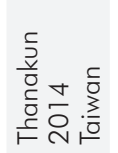 & 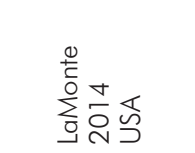 \\
\hline
\end{tabular}




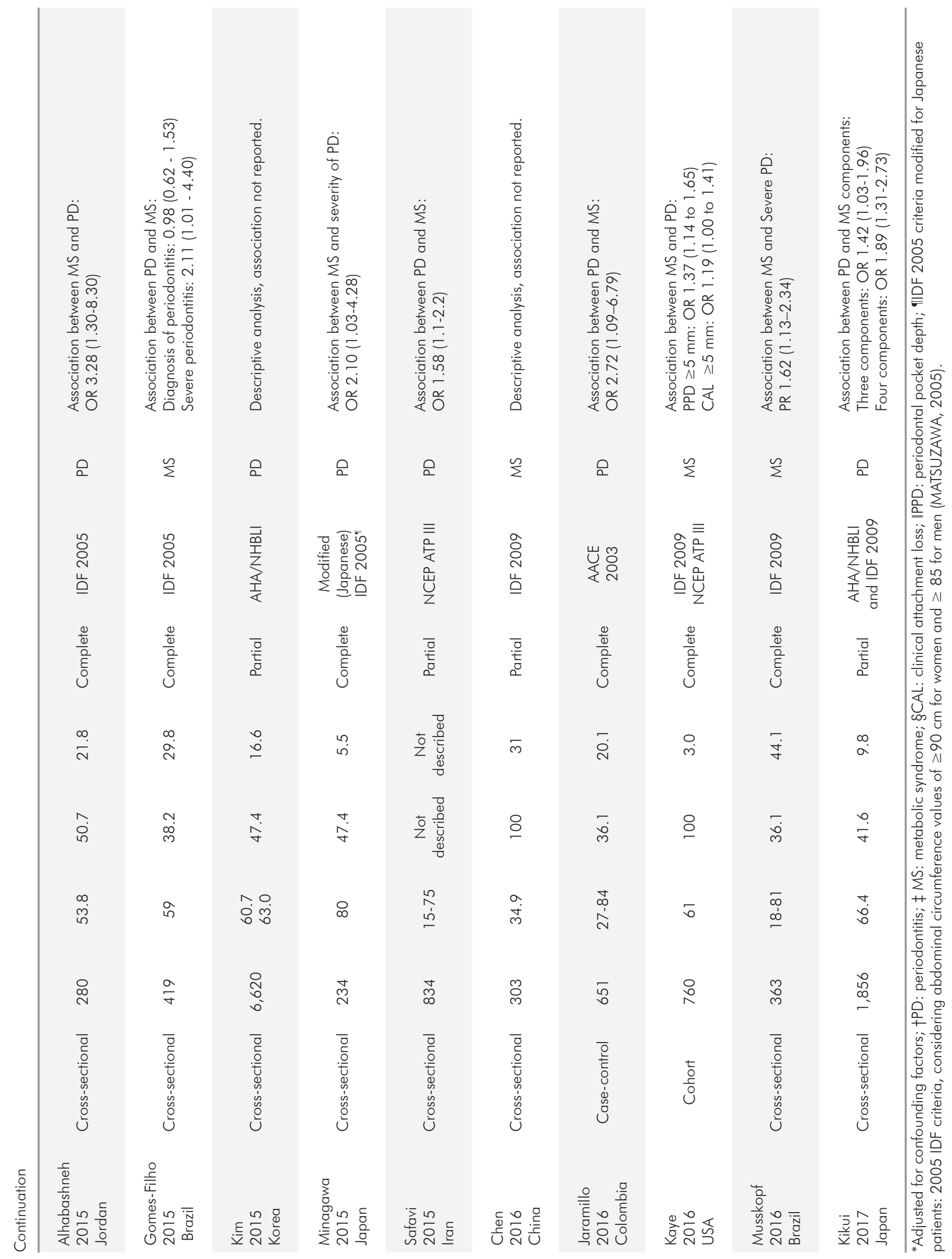


Table 2. Newcastle-Ottawa quality assessment scale adapted to observational studies.

\begin{tabular}{|c|c|c|c|}
\hline Study & Selection & Comparability & Outcome \\
\hline Borges, 2007 & * & * & $* *$ \\
\hline Shimazaki, 2007 & $* *$ & $* *$ & $* *$ \\
\hline D'Aiuto, 2008 & $* * * *$ & $* *$ & $* *$ \\
\hline Kahder, 2008 & $* * *$ & $*$ & $* *$ \\
\hline Kowalski, 2009 & $* *$ & $*$ & $*$ \\
\hline Kushiyama, 2009 & * & $* *$ & $* *$ \\
\hline Li, 2009 & $* *$ & * & $* *$ \\
\hline Morita, 2009 & $* *$ & $*$ & $* *$ \\
\hline Adriankaja, 2010 & $* * *$ & $* *$ & $* *$ \\
\hline Benguigui, 2010 & $* * * *$ & $* *$ & $* *$ \\
\hline Han, 2010 & $* * *$ & $* *$ & $* *$ \\
\hline Morita, 2010 & $* *$ & $* *$ & $* *$ \\
\hline Timonen, 2010 & $* * *$ & $*$ & $*$ \\
\hline Bracho, 2011 & $* *$ & * & $*$ \\
\hline Chen, 2011 & $* *$ & ** & $*$ \\
\hline Li, 2011 & $* *$ & * & * \\
\hline Kwon, 2011 & $* *$ & $* *$ & $* *$ \\
\hline Fukui, 2012 & $* * *$ & $* *$ & $* * *$ \\
\hline Yu, 2012 & $* *$ & $* *$ & $* *$ \\
\hline Sora, 2013 & $* * *$ & $* *$ & $* * *$ \\
\hline Furuta, 2013 & $* * * *$ & $*$ & $* *$ \\
\hline Thanakun, 2014 & $* *$ & * & $*$ \\
\hline La Monte, 2014 & $* * * *$ & $* *$ & ** \\
\hline Alhabashneh, 2015 & $* * *$ & $* *$ & $* * *$ \\
\hline Gomes-Filho, 2015 & $* * *$ & $* *$ & $* * *$ \\
\hline Kim, 2015 & $* * *$ & * & $* *$ \\
\hline Minagawa, 2015 & $* * *$ & $* *$ & $* *$ \\
\hline Safavi, 2015 & $* * *$ & * & ** \\
\hline Chen, 2016 & $* * *$ & $*$ & $* *$ \\
\hline Jaramillo, 2016 & $* * *$ & $* *$ & $* *$ \\
\hline Kaye, 2016 & $* * *$ & $* *$ & $* *$ \\
\hline Musskopf, 2016 & $* * *$ & $* *$ & $* *$ \\
\hline Kikui, 2017 & $* * *$ & $* *$ & $* *$ \\
\hline
\end{tabular}

Scale ranges between zero and nine stars. Highest quality studies awarded maximum of four stars for selection, three stars for outcome and two stars for comparability.
1.19-1.61; $\mathrm{I}^{2}=91.3 \%$ ) for NCEP ATP III, 1.28 (95\%CI 1.07$\left.1.53 ; \mathrm{I}^{2}=85.9 \%\right)$ for IDF 2005, and 1.49 (95\%CI 1.22-1.82; $\mathrm{I}^{2}=93.7 \%$ ) for the IDF 2009 criteria (Figure 4). The authors also evaluated if study quality could be responsible for the heterogeneity observed. The evaluation of six studies with higher scores in the Newcastle-Ottawa quality assessment scale $16,23,37,41,42,47$ did not decrease the heterogeneity $\left(\mathrm{I}^{2}=81.4 \%\right.$; $\left.\mathrm{p}<0.001\right)$.

There was evidence of publication bias, as demonstrated by the funnel plot, Egger's regression test $(p=0.03)$ and Begg's test ( $p=0.005$; Figure 5$)$.

\section{Discussion}

The present findings suggest that individuals with MS are 38\% more likely to have PD than individuals without this condition. This meta-analysis was associated with significant heterogeneity, which may be attributed to variability across the studies, in regard to PD diagnosis (complete vs. partial dental examination). Our results corroborate those of the single meta-analysis, which also assessed the association between MS and PD, and which reported an OR of 1.90 (95\%CI 1.54-2.34). ${ }^{21}$ The main limitation of this meta-analysis was the inclusion of studies with PD diagnosed by both clinical and radiographic methods. Considering that low-grade inflammatory status accounts for the biological plausibility of the relationship between MS and PD, the clinical examination should be preferred in this scenario, since the presence of inflammation in periodontal tissues cannot be assessed by radiologic methods. Four studies included in the previous systematic review ${ }^{21}$ were not included in the present study, because they used radiographic methods for PD diagnosis, ${ }^{56,57}$ or lacked information regarding PD or MS diagnosis criteria. ${ }^{58,59}$ The authors considered this limitation and performed a subgroup analysis, dividing the studies into two categories: those with secure PD diagnosis, defined by the presence of severe PD defined both clinically and radiographically, and those with insecure PD diagnosis, and less severe or not well-defined cases in the original study.

Several studies in the literature have investigated the relationship between MS and PD. However, 


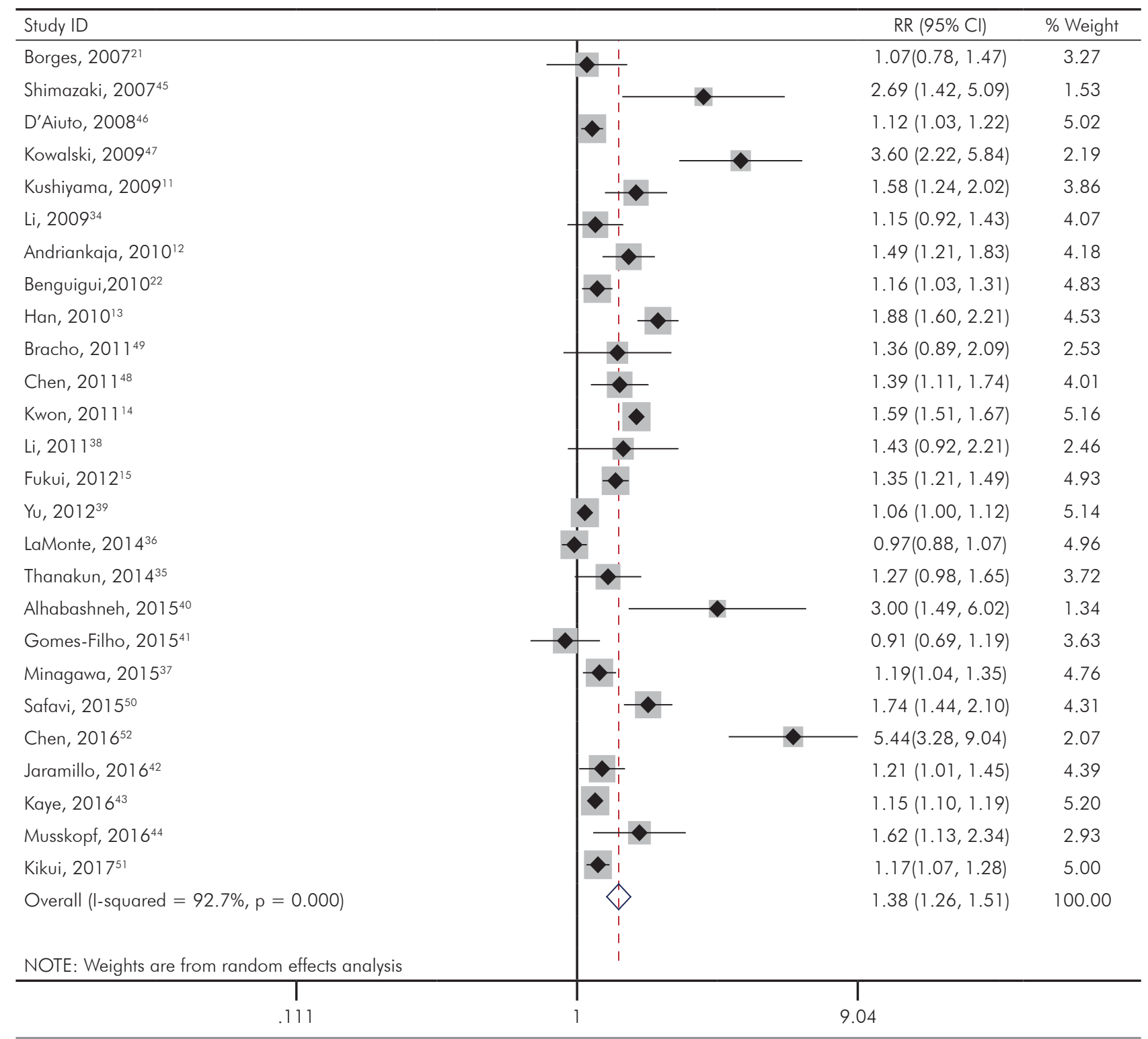

Figure 2. Meta-analyses of the association between periodontal diseases and metabolic syndrome.

the results of these studies have been widely discrepant. Whereas a number of them have reported positive associations between these two conditions, ${ }^{12,13,14,15,16,21}$ other investigations have found no relationship between them ${ }^{22,23}$. Reasons for the variability in results include differences in diagnostic criteria for PD and MS, the involvement of untrained examiners in diagnosing $P D$, the improper control of confounding factors and the presence of selection bias.

Our meta-analysis showed significant heterogeneity, which was explored by several methods. A decrease in heterogeneity was observed when only studies using complete dental examination were considered ( $\mathrm{I}^{2}$ for all studies: $92.7 \%$ and for complete dental examination: $70.6 \%$, indicating that studies using complete periodontal examination presented more reliable estimates. The higher variability found in studies using partial dental examination $\left(\mathrm{I}^{2}=\right.$ $90.8 \%$ ) may be attributed to erroneous diagnosis of these individuals. The extension and severity of PD should be assessed by a full six-site examination, considered the gold standard for PD. ${ }^{60}$ Half of the studies conducted partial examinations, which are known 




Figure 3. Subgroup analyses with complete and partial periodontal examination.

to underestimate the prevalence of $\mathrm{PD} .{ }^{60}$ In addition to variability in the examination protocol used to diagnose PD, the criteria used to detect this condition differed across the studies. Eleven studies used CPI criteria to diagnose the disorder. The Community Periodontal Index of Treatment Needs $(\mathrm{CPITN})^{54}$ was initially developed to assess the treatment needs of patients with $\mathrm{PD}$, and requires ten teeth to be checked for gingival bleeding, supra- and subgingival calculus and periodontal pockets (classified according to size, namely those measuring between 4 and $5 \mathrm{~mm}$ and those measuring $6 \mathrm{~mm}$ or more). WHO recommendations were 


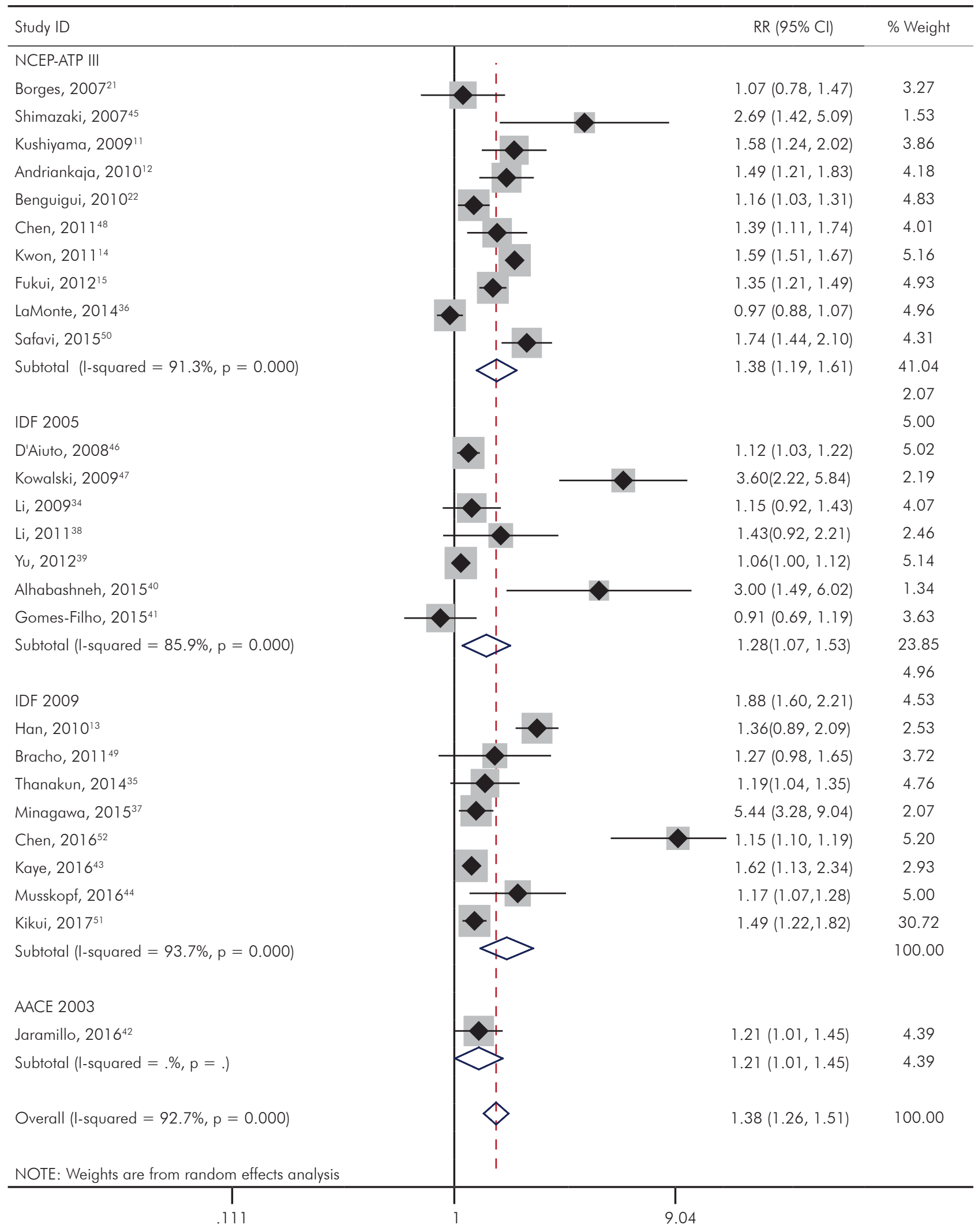

Figure 4. Subgroup analyses with criteria used for metabolic syndrome diagnosis. 


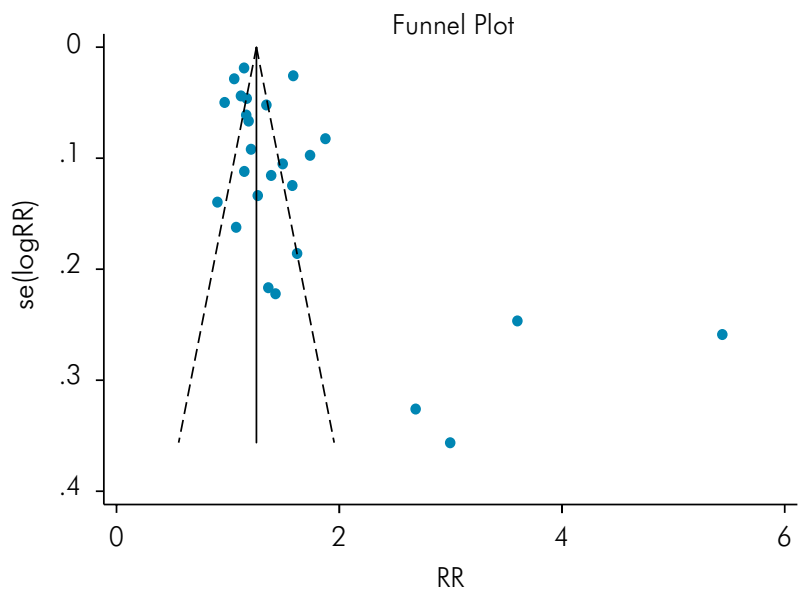

Figure 5. Funnel plot to investigate publication bias.

later amended to include the required measurement of periodontal attachment loss, leading to the renaming of the diagnostic index as CPI (Community Periodontal Index). Although the CPI was not initially designed for use in epidemiological studies, it is widely used in this type of research, although it has proved deficient in assessing the periodontal conditions of several populations reliably. ${ }^{61}$ This low reliability may be attributed to its nature as a partial exam, and of investigating symptoms in a hierarchical sequence.

It is reasonable to think that different MS diagnostic criteria could account for the variability in the studies. For example, although the NCEP ATP III criteria are used by a number of studies, they do not account for population differences in body composition when defining abdominal circumference cut points. The existence of documented differences between the body composition of individuals of different ethnicities ${ }^{62}$ requires population-specific visceral fat cut-offs to be established, as suggested by the IDF and AHA/NHBLI in $2005 .{ }^{63}$ In fact, the 2009 guidelines set in consensus by these institutions established population-specific abdominal circumference cut points. ${ }^{18,19}$ NCEP ATP III criteria may underestimate the prevalence of MS in some populations, as has been found in some studies of Asian individuals ${ }^{12,15,16,49}$ for whom specific cut points were later recommended. ${ }^{63,64}$ However, the variability among studies was not explained by the different MS diagnostic criteria used in the present study.

In addition to investigating the association between PD and MS, some authors also studied the association between PD and specific features of MS. When analyzing the factors separately, the results ranged from the absence of an association to an adjusted OR up to 1.8 (95\%CI 1.2-2.8) for elevated abdominal circumference, ${ }^{46} 2.20$ (95\%CI 1.40- 3.60) for low HDL cholesterol, ${ }^{46} 1.59$ (95\%CI 1.20-2.11) for hypertension, ${ }^{12} 2.20$ (95\%CI 1.3-3.9) for alterations in glucose homeostasis, ${ }^{46}$ and a raw OR of 1.38 (95\%CI 1.17-1.62) for hypertriglyceridemia. ${ }^{15}$ Since these results are similar to those found for MS by these and other authors, ${ }^{21}$ the discussion regarding the relevance of the syndrome persists. The issue of whether MS is more than a combination of its individual components remains controversial..$^{65}$ Nevertheless, treatment for one of these individual conditions could have an effect on the other, thus enhancing the treatment benefits and optimizing the effects of the intervention on the patient's health.

The nature of the present review, with the inclusion of mainly cross-sectional studies, may be considered a limitation of this meta-analysis, since no cause and effect relations could be established between the two conditions. It should also be acknowledged that unpublished studies and individual studies with quality limitations may still be relevant, despite the best efforts to conduct a broad search, and despite the lack of statistical evidence of bias.

\section{Conclusion}

In conclusion, considering its limitations, this systematic review with meta-analysis suggests an association between MS and PD. Further research in this field could include prospective studies conducted to establish cause and effect relations between these two conditions, and whether specific treatments could influence the development of both conditions.

\section{Acknowledgements}

This study received the support of Conselho Nacional de Desenvolvimento Científico e Tecnológico (CNPq; grant number: 482089/2012-1). CBL, JLG and RVO were recipients of $\mathrm{CNPq}$ scholarships (PQ).

This manuscript is dedicated to the memory of our dear colleague, mentor, and coauthor Jorge Luiz Gross, who died in May 2017. 
Daudt LD, Musskopf ML, Mendez M, Remonti LLR, Leitão CB, Gross JL et al.

\section{References}

1. Albandar JM. Periodontal diseases in North America. Periodontol 2000. 2002;29(1):31-69. https://doi.org/10.1034/j.1600-0757.2002.290103.x

2. Corbet EF, Zee KY, Lo EC. Periodontal diseases in Asia and Oceania. Periodontol 2000. 2002;29(1):122-52. https://doi.org/10.1034/j.1600-0757.2002.290107.x

3. Gjermo P, Rösing CK, Susin C, Oppermann R. Periodontal diseases in Central and South America. Periodontol 2000. 2002;29(1):70-8. https://doi.org/10.1034/i.1600-0757.2001.290104.x

4. Sheiham A, Netuveli GS. Periodontal diseases in Europe. Periodontol 2000. 2002;29(1):104-21. https://doi.org/10.1034/j.1600-0757.2002.290106.x

5. Kassebaum NJ, Smith AG, Bernabé E, Fleming TD, Reynolds AE, Vos $T$ et al. Global, regional, and national prevalence, incidence, and disability-adjusted life years for oral conditions for 195 countries, 1990-2015: a systematic analysis for the global burden of diseases, injuries, and risk factors. J Dent Res. 2017 Apr;96(4):380-7. https://doi.org/10.1177/0022034517693566

6. Loos BG, Craandijk J, Hoek FJ, Wertheimvan Dillen PM, Velden U. Elevation of systemic markers related to cardiovascular diseases in the peripheral blood of periodontitis patients. J Periodontol. 2000 Oct;71(10):1528-34. https://doi.org/10.1902/jop.2000.71.10.1528

7. Bizzarro S, Velden U, Heggeler JM, Leivadaros E, Hoek FJ, Gerdes VE et al. Periodontitis is characterized by elevated PAI-1 activity. J Clin Periodontol. 2007 Jul;34(7):574-80. https://doi.org/10.1111/j.1600-051X.2007.01095.x

8. D'Aiuto F, Parkar M, Andreou G, Suvan J, Brett PM, Ready $D$ et al. Periodontitis and systemic inflammation: control of the local infection is associated with a reduction in serum inflammatory markers. J Dent Res. 2004 Feb;83(2):156-60. https://doi.org/10.1177/154405910408300214

9. Tonetti MS, Van Dyke TE. Periodontitis and atherosclerotic cardiovascular disease: consensus report of the Joint EFP/AAP Workshop on Periodontitis and Systemic Diseases. J Periodontol. 2013 Apr;84(4 Suppl):S24-9. https://doi.org/10.1902/jop.2013.1340019

10. Gorman A, Kaye EK, Apovian C, Fung TT, Nunn M, Garcia RI. Overweight and obesity predict time to periodontal disease progression in men. J Clin Periodontol. 2012 Feb;39(2):107-14. https://doi.org/10.1111/j.1600-051X.2011.01824.x

11. Nibali L, D'Aiuto F, Griffiths G, Patel K, Suvan J, Tonetti MS. Severe periodontitis is associated with systemic inflammation and a dysmetabolic status: a case-control study. J Clin Periodontol. 2007 Nov;34(11):931-7. https://doi.org/10.1111/j.1600-051X.2007.01133.x
12. Kushiyama M, Shimazaki Y, Yamashita Y. Relationship between metabolic syndrome and periodontal disease in Japanese adults. J Periodontol. 2009 Oct;80(10):1610-5. https://doi.org/10.1902/jop.2009.090218

13. Andriankaja OM, Sreenivasa S, Dunford R, DeNardin E. Association between metabolic syndrome and periodontal disease. Aust Dent J. 2010 Sep;55(3):252-9. https://doi.org/10.1111/j.1834-7819.2010.01231.x

14. Han DH, Lim SY, Sun BC, Paek D, Kim HD. The association of metabolic syndrome with periodontal disease is confounded by age and smoking in a Korean population: the Shiwha-Banwol Environmental Health Study. J Clin Periodontol. 2010 Jul;37(7):609-16. https://doi.org/10.1111/j.1600-051X.2010.01580.x

15. Kwon YE, Ha JE, Paik DI, Jin BH, Bae KH. The relationship between periodontitis and metabolic syndrome among a Korean nationally representative sample of adults. J Clin Periodontol. 2011 Sep;38(9):781-6. https://doi.org/10.1111/j.1600-051X.2011.01756.x

16. Fukui N, Shimazaki Y, Shinagawa T, Yamashita Y. Periodontal status and metabolic syndrome in middleaged Japanese. J Periodontol. 2012 Nov;83(11):1363-71. https://doi.org/10.1902/jop.2012.110605

17. Eckel RH, Grundy SM, Zimmet PZ. The metabolic syndrome. Lancet. 2005 Apr;365(9468):1415-28. https://doi.org/10.1016/S0140-6736(05)66378-7

18. Alberti KG, Eckel RH, Grundy SM, Zimmet PZ, Cleeman JI, Donato $\mathrm{KA}$ et al. Harmonizing the metabolic syndrome: a joint interim statement of the International Diabetes Federation Task Force on Epidemiology and Prevention; National Heart, Lung, and Blood Institute; American Heart Association; World Heart Federation; International Atherosclerosis Society; and International Association for the Study of Obesity. Circulation. 2009 Oct;120(16):1640-5. https://doi.org/10.1161/CIRCULATIONAHA.109.192644

19. Grundy SM, Cleeman JI, Daniels SR, Donato KA, Eckel $\mathrm{RH}$, Franklin BA et al. Diagnosis and management of the metabolic syndrome: an American Heart Association/ National Heart, Lung, and Blood Institute Scientific Statement. Cardiol Rev. 2005 Nov-Dec;13(6):322-7. https://doi.org/10.1161/CIRCULATIONAHA.105.169404

20. Taylor GW, Burt BA, Becker MP, Genco RJ, Shlossman M, Knowler WC, et al. Severe periodontitis and risk for poor glycemic control in patients with non-insulin-dependent diabetes mellitus. J Periodontol. 1996 Oct;67(10S):1085-93. https://doi.org/10.1902/jop.1996.67.10s.1085

21. Nibali L, Tatarakis N, Needleman I, Tu YK, D'Aiuto F, Rizzo $M$ et al. Clinical review: Association between metabolic syndrome and periodontitis: a systematic review and meta-analysis [doi]. J Clin Endocrinol Metab. 2013 Mar;98(3):913-20. https://doi.org/10.1210/¡c.2012-3552 
- Association between metabolic syndrome and periodontitis: a systematic review and meta-analysis

22. Borges PK, Gimeno SG, Tomita NE, Ferreira SR. [Prevalence and characteristics associated with metabolic syndrome in Japanese-Brazilians with and without periodontal disease]. Cad Saude Publica. 2007 Mar;23(3):657-68. https://doi.org/10.1590/S0102-311X2007000300024

23. Benguigui $C$, Bongard V, Ruidavets JB, Chamontin B, Sixou $M$, Ferrières $J$ et al. Metabolic syndrome, insulin resistance, and periodontitis: a cross-sectional study in a middle-aged French population. J Clin Periodontol. 2010 Jul;37(7):601-8. https://doi.org/10.1111/j.1600-051X.2010.01571.x

24. Stroup DF, Berlin JA, Morton SC, Olkin I, Williamson GD, Rennie $D$ et al. Meta-analysis of observational studies in epidemiology: a proposal for reporting.. JAMA. 2000 Apr;283(15):2008-12. https://doi.org/10.1001/jama.283.15.2008

25. Wells GA, Shea B, O'Connell D, Peterson J, Welch V, Losos $M$ et al. The Newcastle-Ottawa Scale (NOS) for assessing the quality of nonrandomized studies in meta-analyses. Ottawa: The Ottawa Hospital Research Institute; 2013 [cited 2013 Jan 1], Available from: http://www.ohri.ca/programs/clinical_ epidemiology/oxford.htm

26. Higgins JP, Thompson SG. Quantifying heterogeneity in a meta-analysis. Stat Med. 2002 Jun;21(11):1539-58. https://doi.org/10.1002/sim.1186

27. Stang A. Critical evaluation of the Newcastle-Ottawa scale for the assessment of the quality of nonrandomized studies in meta-analyses. Eur J Epidemiol. 2010 Sep;25(9):603-5. https://doi.org/10.1007/s10654-010-9491-z

28. Khader Y, Khassawneh B, Obeidat B, Hammad M, ElSalem $\mathrm{K}$, Bawadi $\mathrm{H}$ et al. Periodontal status of patients with metabolic syndrome compared to those without metabolic syndrome. J Periodontol. 2008 Nov;79(11):2048-53. https://doi.org/10.1902/jop.2008.080022

29. Morita T, Ogawa Y, Takada K, Nishinove N, Sasaki $Y$, Motohashi $M$ et al. Association between periodontal disease and metabolic syndrome. J Public Health Dent. 2009;69(4):248-53. https://doi.org/10.1111/j.1752-7325.2009.00130.x

30. Morita T, Yamazaki Y, Mita A, Takada K, Seto M, Nishinoue $\mathrm{N}$ et al. A cohort study on the association between periodontal disease and the development of metabolic syndrome. J Periodontol. 2010 Apr;81(4):512-9. https://doi.org/10.1902/jop.2010.090594

31. Timonen P, Niskanen M, Suominen-Taipale L, Jula A, Knuuttila M, Ylöstalo P. Metabolic syndrome, periodontal infection, and dental caries. J Dent Res. 2010 Oct;89(10):1068-73. https://doi.org/10.1177/0022034510376542

32. Sora ND, Marlow NM, Bandyopadhyay D, Leite RS, Slate EH, Fernandes JK. Metabolic syndrome and periodontitis in Gullah African Americans with type 2 diabetes mellitus. J Clin Periodontol. 2013 Jun;40(6):599-606. https://doi.org/10.1111/jcpe.12104

33. Furuta $M$, Shimazaki Y, Takeshita T, Shibata Y, Akifusa $S$, Eshima $\mathrm{N}$ et al. Gender differences in the association between metabolic syndrome and periodontal disease: the
Hisayama Study. J Clin Periodontol. 2013 Aug;40(8):743-52. https://doi.org/10.1111/jicpe.12119

34. Kim YH, Kim DH, Lim KS, Ko BJ, Han BD, Nam GE et al. Oral health behaviors and metabolic syndrome: the 2008-2010 Korean National Health and Nutrition Examination Survey. Clin Oral Investig. 2014;18(5):1517-24. https://doi.org/10.1007/s00784-013-1112-2

35. Li P, He L, Sha YQ, Luan QX. Relationship of metabolic syndrome to chronic periodontitis. J Periodontol. 2009 Apr;80(4):541-9. https://doi.org/10.1902/jop.2009.080387

36. Thanakun S, Watanabe $H$, Thaweboon S, Izumi $\mathrm{Y}$. Association of untreated metabolic syndrome with moderate to severe periodontitis in Thai population. J Periodontol. 2014 Nov;85(11):1502-14. https://doi.org/10.1902/jop.2014.140105

37. LaMonte MJ, Williams AM, Genco RJ, Andrews CA, Hovey KM, Millen AE et al. Association between metabolic syndrome and periodontal disease measures in postmenopausal women: the Buffalo OsteoPerio study. J Periodontol. 2014 Nov;85(11):1489-501. https://doi.org/10.1902/jop.2014.140185

38. 38. Minagawa K, Iwasaki M, Ogawa H, Yoshihara A, Miyazaki $\mathrm{H}$. Relationship between metabolic syndrome and periodontitis in 80 -year-old Japanese subjects. J Periodontal Res. 2015 Apr;50(2):173-9. https://doi.org/10.1111/ire.12190

39. Li P. Zhang da K, Zhang J, Chen L [Detection of the parameters for early atherosclerosis in patients with metabolic syndrome and periodontitis]. Beijing Da Xue Xue Bao. 2011;43(1):34-9. Chinese.

40. Yu ZR, Liu LS, Luan QX, Wang XY, Li P, Sha YQ et al. [Correlation between periodontitis and metabolic syndrome of the middle-aged and aged population in Shijingshan community of Beijing]. Beijing Da Xue Xue Bao Yi Xue Ban. 2012 Aug;44(4):633-8. Chinese.

41. Alhabashneh R, Khader Y, Herra Z, Asa'ad F, Assad $F$. The association between periodontal disease and metabolic syndrome among outpatients with diabetes in Jordan. J Diabetes Metab Disord. 2015 Aug;14(1):67. https://doi.org/10.1186/s40200-015-0192-8

42. Gomes-Filho IS, das Mercês MC, de Santana Passos-Soares J, Seixas da Cruz S, Teixeira Ladeia AM, Trindade SC et al. Severity of Periodontitis and Metabolic Syndrome: Is There an Association? J Periodontol. 2016 Apr;87(4):357-66. https://doi.org/10.1902/jop.2015.150367

43. Jaramillo A, Contreras A, Lafaurie GI, Duque A, Ardila CM, Duarte $S$ et al. Association of metabolic syndrome and chronic periodontitis in Colombians. Clin Oral Investig. 2017 Jun;21(5):1537-44. https://doi.org/10.1007/s00784-016-1942-9

44. Kaye EK, Chen N, Cabral HJ, Vokonas P, Garcia RI. Metabolic Syndrome and Periodontal Disease Progression in Men. J Dent Res. 2016 Jul;95(7):822-8. https://doi.org/10.1177/0022034516641053 
45. Musskopf ML, Daudt LD, Weidlich P, Gerchman F, Gross JL, Oppermann RV. Metabolic syndrome as a risk indicator for periodontal disease and tooth loss. Clin Oral Investig. 2017 Mar;21(2):675-83. https://doi.org/10.1007/s00784-016-1935-8

46. Shimazaki Y, Saito T, Yonemoto K, Kiyohara Y, lida M, Yamashita Y. Relationship of metabolic syndrome to periodontal disease in Japanese women: the Hisayama Study. J Dent Res. 2007 Mar;86(3):271-5. https://doi.org/10.1177/154405910708600314

47. D'Aiuto F, Sabbah W, Netuveli G, Donos N, Hingorani AD, Deanfield J et al. Association of the metabolic syndrome with severe periodontitis in a large U.S. population-based survey. J Clin Endocrinol Metab. 2008 Oct;93(10):3989-94. https://doi.org/10.1210/jc.2007-2522

48. Kowalski M, Brocka E, Barylski M, Kowalczyk E, Pawlicki $\mathrm{L}$, Kowalski J. [Assessment of the periodontal state in subjects with metabolic syndrome]. Pol Merkuriusz Lek. 2009;26(156):620-5. Polish.

49. Chen LP, Hsu SP, Peng YS, Chiang CK, Hung KY. Periodontal disease is associated with metabolic syndrome in hemodialysis patients. Nephrol Dial Transplant. 2011 Dec;26(12):4068-73. https://doi.org/10.1093/ndt/gfr209

50. Bracho R, Ruiz ME, Bohorquez D, Perez L, Rodriguez E, Rivera $L$ et al. [Oral hygiene and periodontal conditions in patients with metabolic syndrome]. Rev Latinoam Hipertens. 2011;6(4):60-6. Spanish.

51. Safavi F, Yousefzadeh G, Shokoohi M, Safavi S, Najafipour $H$, Farokhi MS. Prevalence of metabolic syndrome in patients with periodontal disease. J Kerman Univ Med Sci. 2015;22(3):229-39.

52. Kikui M, Ono T, Kokubo Y, Kida M, Kosaka T, Yamamoto $M$ et al. Relationship between metabolic syndrome and objective masticatory performance in a Japanese general population: the Suita study. J Dent. 2017 Jan;56:53-7. https://doi.org/10.1016/i.jdent.2016.10.014

53. Chen X, Xie L, Liu Y, Chen D, Yu Q, Gan X et al. Metabolic Syndrome and Periodontal Disease Among Civilian Pilots. Aerosp Med Hum Perform. 2016 Dec;87(12):1016-20. https://doi.org/10.3357/AMHP.4654.2016

54. Ainamo J, Barmes D, Beagrie G, Cutress T, Martin J, SardoInfirri J. Development of the World Health Organization (WHO) community periodontal index of treatment needs (CPITN). Int Dent J. 1982 Sep;32(3):281-91.
55. Page RC, Eke Pl. Case definitions for use in population-based surveillance of periodontitis. J Periodontol. 2007 Jul;78/7 Suppl):1387-99. https://doi.org/10.1902/jop.2007.060264

56. Nesbitt MJ, Reynolds MA, Shiau H, Choe K, Simonsick EM, Ferrucci L. Association of periodontitis and metabolic syndrome in the Baltimore Longitudinal Study of Aging. Aging Clin Exp Res. 2010 Jun;22(3):238-42. https://doi.org/10.1007/BF03324802

57. Bensley L, VanEenwyk J, Ossiander EM. Associations of selfreported periodontal disease with metabolic syndrome and number of self-reported chronic conditions.

Prev Chronic Dis. 2011 May;8(3):A50.

58. Pozharitskaia MM, Simakova TG, Starosel'tseva LK, Kirienko VV. [Inflammatory diseases of the parodontium in patiens with metabolic syndrome]. Stomatologia (Mosk). 2004;83(6):13-6. Russian.

59. Guize L, Thomas F, Pannier B, Bean K, Danchin N, Bénétos A. [Metabolic syndrome: prevalence, risk factors and mortality in a French population of 62000 subjects]. Bull Acad Natl Med. 2006 Mar;190(3):685-97. French.

60. Susin C, Kingman A, Albandar JM. Effect of partial recording protocols on estimates of prevalence of periodontal disease. J Periodontol. 2005 Feb;76(2):262-7. https://doi.org/10.1902/jop.2005.76.2.262

61. Bassani DG, da Silva CM, Oppermann RV. Validity of the "Community Periodontal Index of Treatment Needs" (CPITN) for population periodontitis screening. Cad Saude Publica. 2006 Feb;22(2):277-83. https://doi.org/10.1590/S0102-311X2006000200005

62. Tanaka S, Horimai C, Katsukawa F. Ethnic differences in abdominal visceral fat accumulation between Japanese, African-Americans, and Caucasians: a meta-analysis [d]. Acta Diabetol. 2003 Oct;40(0 Suppl 1):S302-4. https://doi.org/10.1007/s00592-003-0093-z

63. Alberti KG, Zimmet P, Shaw J. The metabolic syndrome: a new worldwide definition. Lancet. 2005 Sep;366(9491):1059-62. https://doi.org/10.1016/S0140-6736(05)67402-8

64. Matsuzawa Y, Funahashi T, Nakamura T. The concept of metabolic syndrome: contribution of visceral fat accumulation and its molecular mechanism. J Atheroscler Thromb. 2011;18(8):629-39. https://doi.org/10.5551/jat.7922

65. Kassi E, Pervanidou P, Kaltsas G, Chrousos G. Metabolic syndrome: definitions and controversies. BMC Med. 2011 May;9(1):48. https://doi.org/10.1186/1741-7015-9-48 